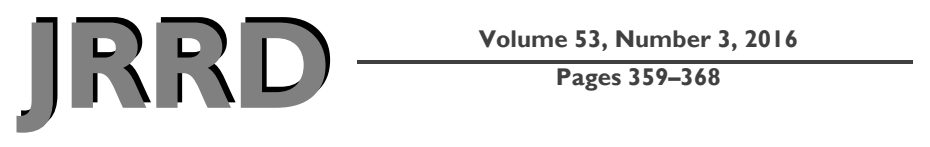

\title{
Effects of high-speed power training on muscle strength and power in patients with multiple sclerosis
}

\author{
Carlos Medina-Perez, PhD; ${ }^{*}$ Fernanda de Souza-Teixeira, PhD ${ }^{2}$ Rodrigo Fernandez-Gonzalo, PhD; ${ }^{3}$ \\ Jose-Aldo Hernandez-Murua, $\mathrm{PhD} ;{ }^{4}$ Jose Antonio de Paz-Fernandez, $\mathbf{P h D}^{\mathbf{5}}$ \\ ${ }^{1}$ University Isabel I, Burgos, Spain; ${ }^{2}$ Department of Physical Education and Health, School of Physical Education, \\ Federal University of Pelotas, Pelotas, Brazil; ${ }^{3}$ Department of Physiology and Pharmacology, Karolinska Institutet, \\ Stockholm, Sweden; ${ }^{4}$ School of Physical Education, Autonomous University of Sinaloa, Sinaloa, Mexico; ${ }^{5}$ Institute of \\ Biomedicine, University of León, León, Spain
}

\begin{abstract}
This study examined the effects of a high-speed power training program in peak muscle power and maximal voluntary isometric contraction (MVIC) of knee extensors in patients with relapsing-remitting multiple sclerosis (MS). Forty patients, 20 women (age $42.8+/-10.3 \mathrm{yr}$ ) and 20 men (age $44.0+/-8.7 \mathrm{yr}$ ) diagnosed with relapsing-remitting MS were randomly assigned, with respect to sex, to either an exercise group or a control group. Participants from the exercise group performed 12 wk of supervised muscle power training of knee extensors. All subjects were tested for MVIC and peak muscle power at baseline and after the training intervention. A strain gauge was used to measure the MVIC, and peak muscle power was assessed with a linear encoder at five relative loads. The training-related effects were assessed using a $t$-test. The results showed no significant changes in the control group from baseline to postintervention evaluation. In contrast, the exercise group significantly increased MVIC $(10.8 \% ; p<0.05)$ and muscle power at $40,50,60,70$, and $80 \%$ of the MVIC by 21.8 , $14.5,17.3,19.4$, and $22.3 \%$, respectively $(p<0.01)$, after the training. These findings suggest that $12 \mathrm{wk}$ of high-speed power training improve both MVIC and muscle power at five different loads in patients with relapsing-remitting MS.
\end{abstract}

Key words: disability, encoder, exercise prescription, leg performance, lower limb, multiple sclerosis, muscle power, muscle strength, rehabilitation, resistance training.

\section{INTRODUCTION}

Patients with multiple sclerosis (MS) experience a range of symptoms related to mobility restrictions in the lower limbs that often result in impaired mobility [1] and high numbers of falls [2], which may lead to a reduction in their physical activity [3] and a lowering of their quality of life [4]. These symptoms are related to neuromuscular disorders such as impaired muscle strength [5-6] and muscle weakness in the lower limbs [7]. It seems these impairments are exacerbated during dynamic contractions at high velocities [7-9] due to the significant effect of the MS disease on lower-limb muscle power.

Muscle power is the relationship between the force generated and the velocity at which the movement is performed [10]. Patients with MS present reduced lower-limb muscle power capacity compared with nondisabled counterparts [5]. This deficit is due to deficient muscle mechanical parameters related to both neural $[6,11]$ and structural

\footnotetext{
Abbreviations: $\mathrm{CG}=$ control group, $\mathrm{CI}=$ confidence interval, $\mathrm{EG}=$ exercise group, $\mathrm{MS}=$ multiple sclerosis, $\mathrm{MVIC}=$ maximal voluntary isometric contraction.

*Address all correspondence to Carlos Medina-Perez, PhD; University Isabel I, Calle Fernán González, $n^{\circ}$ 76. PC: 09003 Burgos, Spain; +34-987-293016.

Email: carlos.medina@ui1.es or carlosmedinaper85@gmail.com http://dx.doi.org/10.1682/JRRD.2014.08.0186
} 
[12] mechanisms. Indeed, previous studies have shown loss of muscle mass, abnormal distribution of muscle fiber types, reduced ability to fully activate motor units, and reduced rate of force development in patients with MS when compared with nondisabled controls $[5,13]$.

As it occurs in patients with MS, muscle power is reduced in the elderly. In this population, muscle power is a reliable measure of muscle performance [14] and a strong physiological predictor of functional limitations [14-16]. Thus, higher muscle power in the legs is usually related to preserved physical function [17-18]. Muscle power is also important to increase safety during certain functional tasks in frail populations (e.g., climbing stairs or stabilizing the body after losing balance) [19-21]. Hence, increasing the ability to produce power at lower or higher external resistances in the lower limbs is a key factor in everyday task performance [20].

Resistance training interventions have shown efficacy in improving muscle power performance in the elderly and patients with MS [19-20,22-23]. It is believed that resistance training based on high velocity improves muscle power to a greater extent than high-load resistance training [24]. Indeed, using light-to-moderate external loads $(30 \%-75 \%$ of 1 maximum repetition for lower-body exercises) [25-27] and performing movements at maximal velocity [25] increase muscle power to a greater extent than other exercise training interventions. There are plenty of studies describing the effects of highspeed resistance exercise on aging populations, and it is relatively well known that high-speed power training affects the velocity component of peak power production [20]. Thus, this training model has become an important therapeutic tool for improving lower-limb muscle performance and functional capacity in nondisabled elderly subjects [26-30]. In contrast, this training methodology has not yet been used in patients with MS.

Although some reports have shown that progressive resistance exercise and maximal strength training induce positive adaptations in muscle power, muscle strength, and functional capacity in patients with MS [31], the limited evidence precludes any firm conclusion. Thus, the present study was designed to examine the effects of 12 wk of muscle power training on peak muscle power and maximal voluntary isometric contraction (MVIC) of knee extensors in patients with MS. We hypothesized that 12 wk of high-speed power training would increase MVIC and peak muscle power.

\section{METHODS}

\section{Participants}

The study was approved by the Research Ethics Committee at the University of León. Participants were recruited among five MS rehabilitation centers within the region of Castilla y León, Spain. We contacted 108 patients (47 men and 61 women) to take part in the study. The patient inclusion criteria were age between 18 and $65 \mathrm{yr}$, a confirmed disease diagnosis of relapsing-remitting MS by a neurologist according to McDonald criteria [32], Expanded Disability Status Scores between 3.0 and 6.0, ability to walk at least $20 \mathrm{~m}$ with or without minimal assistance (e.g., cane), no previous experience with resistance or muscle power training, and no involvement in other structured physical or recreational fitness program within the last 12 wk. In addition, patients were excluded if they had other conditions that might have affected muscle function (e.g., recent bone fractures) or the training protocol (e.g., herniated discs).

Of the patients contacted, 77 ( 35 men and 42 women) met the inclusion criteria and volunteered to participate in this study by signing written informed consent. They performed the pretests and were then randomly assigned, with respect to sex, to two different groups: the exercise group (EG) $(n=38$, age 34-64 yr) or the control group (CG) ( $n=39$, age 28-55 yr). During the study, 18 patients from the EG were excluded because they participated in less than 75 percent of the sessions in the training program $(n=6)$, they did not participate in the testing session $(n=10)$, or they dropped out because of circumstances unrelated to the training protocol $(n=2)$. In addition, 19 patients from the CG were excluded because they participated in a structured physical activity program $(n=8)$ or they did not participate in the testing session $(n=11)$. Hence, 40 patients were included in the final analysis $(E G=20 ; C G=20)$. The flow diagram of the enrollment procedure is presented in Figure 1.

\section{Study Design}

The intervention period lasted 12 wk. Testing was performed at baseline and after the intervention. During the intervention, the EG performed 12 wk of a high-speed power training program for the knee extensors ( 2 sessions per week). The CG did not follow any structured physical activity program. Both groups followed their habitual daily activities during the experimental period. A muscle power training program, similar to the one 


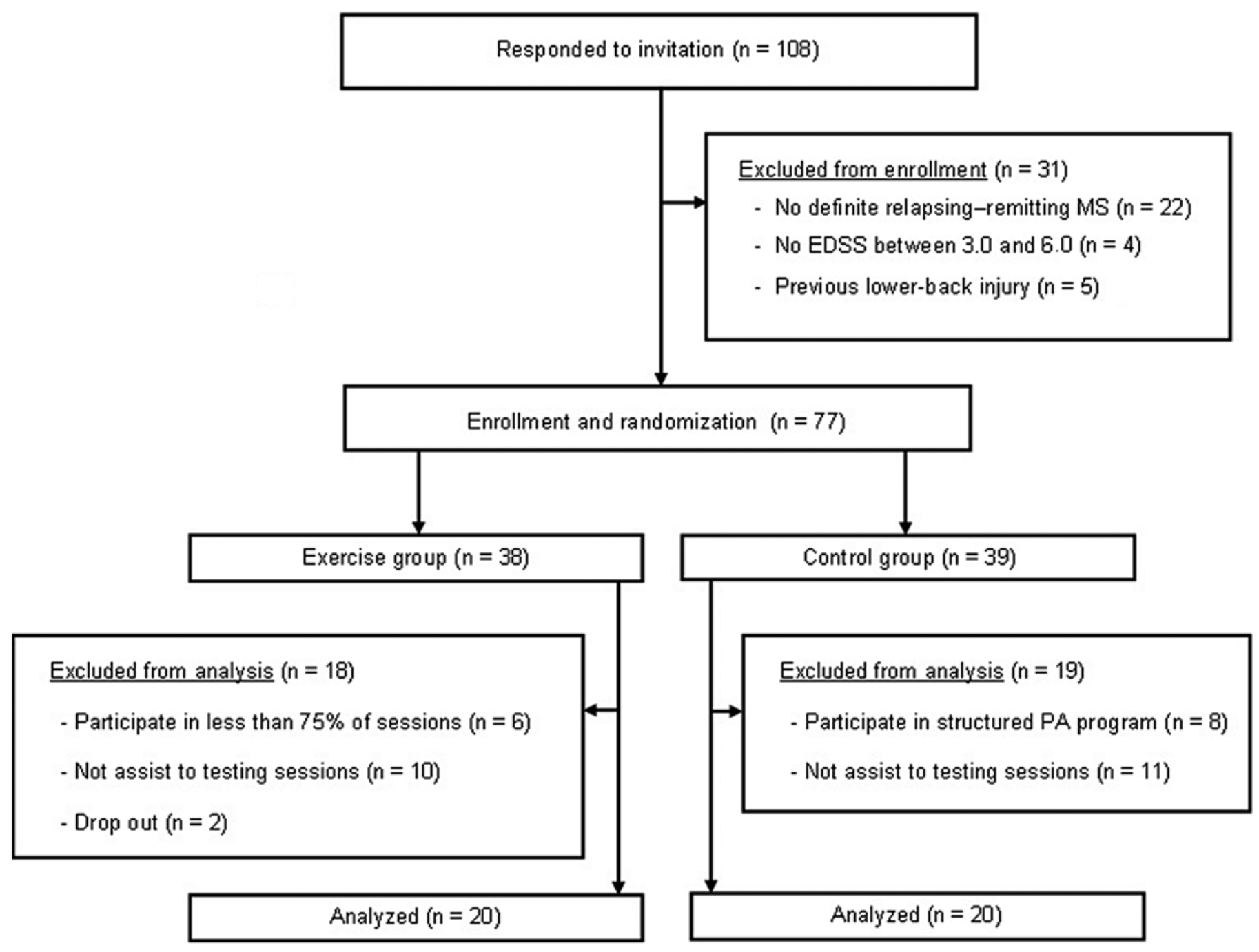

Figure 1.

Flow diagram of enrollment procedure. EDSS = Expanded Disability Status Scale, MS = multiple sclerosis, PA = physical activity.

described in this study, was offered to the CG after completion of this intervention.

\section{Muscle Power Training}

The training protocol is based on previous studies $[22,26]$. Subjects performed knee extension exercise on a weight stack machine (Nevada Pro-T, BH Fitness; Vitoria-Gasteiz, Spain) twice per week for $12 \mathrm{wk}$, with at least $48 \mathrm{~h}$ of rest between sessions. The load (40\%-70\% of MVIC), number of sets (3-4), and number of repetitions (4-10) were adapted across the training period (Table 1). The percentage of load during the training period was calculated based on MVIC data obtained at baseline. Each training session was supervised by a physical therapist and started with a standardized warm-up. Recovery time between sets was $3 \mathrm{~min}$. Subjects were instructed to perform the concentric shortening action "as fast as possible." In contrast, subjects were requested to perform the eccentric lengthening action in a slow controlled manner. If a patient missed a training session, the session was performed on an alternate day if possible. All training sessions took place in MS rehabilitation centers.

\section{Measurement of Outcomes}

Dependent variables included MVIC, maximal torque, and peak muscle power. Outcome measures were assessed 
Table 1.

Power training protocol.

\begin{tabular}{|c|c|c|c|c|c|c|}
\hline Protocol & Week 1-2 & Week 3-4 & Week 5-6 & Week 7-8 & Week 9-10 & Week 11-12 \\
\hline Load (\% of MVIC) & 40 & 50 & 50 & 60 & 60 & 70 \\
\hline Sets per Session $(n)$ & 3 & 3 & 4 & 3 & 4 & 3 \\
\hline Repetitions per Set $(n)$ & 10 & 10 & 6 & 6 & 4 & 4 \\
\hline
\end{tabular}

by researchers who were blind to the patients' group. Each participant was individually informed about the test procedures before initiating them. The testing session was performed in a single session: first, the patient performed the MVIC test, followed by a recovery period of $10 \mathrm{~min}$. Second, each participant carried out the peak power test. Researches gave verbal standard encouragement to maximize motivation in the patients during both tests.

\section{Maximal Voluntary Isometric Contraction Measurement}

The MVIC test was performed with a similar device described for the training program. The test procedure was performed following previous reports [22-23,33]. Isometric leg extension force was measured by a load cell (Globus; Codognè, Italy; sample rate $1,000 \mathrm{~Hz}$ ) during $5 \mathrm{~s}$ with a knee flexion of $90^{\circ}$. Data were collected and analyzed with associated software (Globus Ergo Tester v1.5). During the test, patients were instructed to push as hard as possible from the beginning of the test and then maintain maximal strength against the fixed lever arm of the device for $5 \mathrm{~s}$. Two attempts, separated by $3 \mathrm{~min}$, were carried out by each participant. Only the higher value of both attempts was considered for further analysis. Torque (Newton॰meter) was calculated as the product between the force produced and the individual distance between the axis of rotation of the knee joint and the tibial pad for each participant.

\section{Peak Muscle Power Measurement}

Peak muscle power tests were carried out in the knee extension machine described previously. Peak concentric knee extension power was determined across a spectrum of five submaximal loads relative to MVIC [34], i.e., weight stack loads providing resistance forces equal to 40 , $50,60,70$, and 80 percent of the pretraining MVIC. Subjects completed one set of three full range-of-motion knee extension actions with each load. Subjects rested $2 \mathrm{~min}$ between each set. Subjects were instructed to push the load during the concentric phase "as fast as possible," while the eccentric action was performed slowly. Peak power was calculated from electronic measures of force, displacement, and duration using a linear encoder (Globus Real Power, sample rate $300 \mathrm{~Hz}$ ). Associated software (Globus Real Power v3.11) was used to control for successful trials and to calculate peak power for every repetition. At each load, the repetition showing higher peak power values was used for data analysis. Order of the five loads used was randomized within subjects prior to testing and maintained from pre- to posttesting sessions.

\section{Statistical Analysis}

Data were analyzed using SPSS version 21.0 (IBM Corporation; Armonk, New York). Results are presented as mean $(95 \%$ confidence interval [CI]). A Shapiro-Wilk normality test was used to assess normal data distribution. Time effects within groups for MVIC and peak muscle power were evaluated with a paired $t$-test. After the intervention, relative changes (percentages) between groups were compared with an independent $t$-test. The level of significance was set at $p<0.05$. The effect size statistic was calculated for the measures of the primary outcomes in the experimental group and for outcome measures comparing the EG and CG. To interpret effect sizes, we used Cohen classification, where a value of 0.2 is small, 0.5 is medium, and 0.8 or higher is large [35].

\section{RESULTS}

\section{Subject Characteristics at Baseline}

Descriptive characteristics are shown in Table 2. No significant differences in descriptive characteristics were found between experimental and control groups.

\section{Adherence}

Overall adherence to the training intervention (e.g., exercise group) averaged 22.8 (22.1 to 23.5) sessions from a total of 24 planned sessions. Participants analyzed in the exercise group had to complete more than 75 percent of the sessions included in the training program. 
Table 2.

Subject characteristics at baseline. Data given as mean (95\% confidence interval) unless otherwise noted.

\begin{tabular}{lccc}
\hline \multicolumn{1}{c}{ Characteristic } & EG & CG & p-Value (EG vs CG) \\
\hline Participants $($ male/female) & $20(10 / 10)$ & $20(10 / 10)$ & - \\
Age $(\mathrm{yr})$ & $45.6(41.5-49.6)$ & $41.3(36.6-46.0)$ & 0.16 \\
Weight $(\mathrm{kg})$ & $70.2(64.5-75.9)$ & $72.3(67.3-77.2)$ & 0.58 \\
Height $(\mathrm{cm})$ & $170.1(166.6-173.5)$ & $168.1(164.7-171.5)$ & 0.40 \\
BMI $\left(\mathrm{kg} / \mathrm{m}^{2}\right)$ & $24.3(22.4-26.1)$ & $25.6(23.7-27.5)$ & 0.29 \\
EDSS & $3.9(3.5-4.3)$ & $4.2(3.6-4.7)$ & 0.40 \\
Time Since Diagnosis $(\mathrm{yr})$ & $10.9(7.9-14.0)$ & $10.4(7-13.7)$ & 0.79 \\
Treatment $(n)$ & & & - \\
IFN- $\beta$ la & 10 & 4 & - \\
Glatiramer Acetate & 5 & 9 & - \\
Natalizumab & 3 & 1 & - \\
Fingolimod & 2 & 0 & - \\
Fampridina & 0 & 0 & - \\
Currently No Treatment & 0 & 10 & - \\
Any Technical Help $(n)$ & 11 & 7 & - \\
Cane/One Crutch $(n)$ & 8 & 3 & - \\
Crutches $(n)$ & 2 & & - \\
BMI = body mass index, CG $=$ control group, EDSS = Expanded Disability Status Scale, EG = exercise group, IFN- $\beta$ 1a= interferon beta 1a. & \\
\hline \hline
\end{tabular}

Missed sessions were caused by medical examination $(n=2)$ and injuries not related to the training sessions $(n=1)$. No adverse effects or health problems attributable to the testing and training sessions from the present investigation were noted.

\section{Maximal Voluntary Isometric Contraction and Torque in the Exercise Group}

The EG improved MVIC after the muscle power training period (pretest: $866.4[95 \% \mathrm{CI}=727.1$ to 1,005.6], posttest: 943.1 [95\% CI $=798.1$ to $1,088.2], p<$ $0.01)$, although the effect size was small (0.259). In addition, torque increased in the EG after the training period (pretest: 360.2 [95\% CI $=295.8$ to 424.6$]$, posttest: 392.9 $[95 \% \mathrm{CI}=232.8$ to 461.9$], p<0.01)$. These variables did not change during the study period in the CG (Table 3).

\section{Comparison of Exercise and Control Groups at Baseline and After Intervention}

No significant differences were found in MVIC, torque, and peak muscle power between the $\mathrm{EG}$ and $\mathrm{CG}$ at baseline. After the intervention, the EG increased MVIC by 10.8 percent $(95 \% \mathrm{CI}=4.1$ to 17.5$)$ versus 2.6 percent $(95 \% \mathrm{CI}=-1.3$ to 6.6$)$ in the $\mathrm{CG}(p<0.05)$. The EG increased muscle power at 40 percent of the MVIC by 21.8 percent $(95 \% \mathrm{CI}=7.9$ to 35.7$)$ versus -4.7 percent $(95 \% \mathrm{CI}=-12.6$ to 3.2$)$ in the $\mathrm{CG}(p<$
0.01). Similarly, muscle power at 50 percent of the MVIC increased in the EG by 14.5 percent $(95 \% \mathrm{CI}=5.0$ to 24.0$)$ versus -4.7 percent $(95 \% \mathrm{CI}=-11.6$ to 2.2$)$ in the $\mathrm{CG}(p<0.01)$. The EG increased muscle power at 60 percent of the MVIC by 17.3 percent $(95 \% \mathrm{CI}=8.9$ to $25.6)$ versus -3.4 percent $(95 \% \mathrm{CI}=-12.2$ to 5.4$)$ in the $\mathrm{CG}(p<0.01)$. Muscle power at 70 percent of the MVIC was significantly higher in the EG $(19.4 \%$ [95\% CI $=3.9$ to 34.8$])$ versus $\mathrm{CG}(-10.9 \%$ [95\% $\mathrm{CI}=-20.8$ to -1.0$])$ $(p<0.01)$. Finally, the EG increased muscle power at 80 percent of the MVIC by 22.3 percent $(95 \% \mathrm{CI}=-2.9$ to 47.5$)$ versus -14.2 percent $(95 \% \mathrm{CI}=-28.7$ to 0.4$)$ in the CG $(p<0.01)$ (Figure 2). The effect sizes of 0.711 , $0.49,0.58,0.62$, and 0.44 were medium to large for the changes in peak muscle power, with corresponding percent improvements of 21.8, 14.5, 17.3, 19.4, and 22.3 percent, respectively, relative to baseline scores for the five measures (Table 3).

\section{DISCUSSION}

This novel study assessed the influence of a muscle power training program on muscle strength and power in patients with relapsing-remitting MS. The main finding of the present investigation was that MVIC and muscle power at five submaximal loads was improved after 
JRRD, Volume 53, Number 3, 2016

Table 3.

Muscular performance at baseline and after intervention. Data are given as mean ( $95 \%$ confidence interval).

\begin{tabular}{|c|c|c|c|c|c|c|c|}
\hline \multirow{2}{*}{ Measure } & \multicolumn{2}{|c|}{ Exercise Group } & \multirow{2}{*}{$\begin{array}{c}\text { Change } \\
\text { Baseline- } \\
\text { Posttraining } \\
\text { (\%) }\end{array}$} & \multicolumn{2}{|c|}{ Control Group } & \multirow{2}{*}{$\begin{array}{c}\text { Change } \\
\text { Baseline- } \\
\text { Posttraining } \\
(\%)\end{array}$} & \multirow{2}{*}{ ES } \\
\hline & Baseline & Posttraining & & Baseline & Posttraining & & \\
\hline \multirow[t]{2}{*}{$\overline{\text { MVIC (N) }}$} & 866.4 & 943.1 & 10.8 & 858.5 & 871.0 & 2.6 & 0.714 \\
\hline & 727.1 to $1,005.6$ & 798.1 to $1,088.2^{*}$ & 4.1 to $17.5^{\dagger}$ & 734.2 to 982.9 & 759.4 to 982.6 & -1.3 to 6.6 & \\
\hline \multirow[t]{2}{*}{ Torque $(\mathbf{N} \cdot \mathbf{m})$} & 360.2 & 392.9 & 10.8 & 353.8 & 358.3 & 2.6 & 0.714 \\
\hline & 295.8 to 424.6 & 323.8 to $461.9^{*}$ & 4.1 to $17.5^{\dagger}$ & 296.6 to 411.1 & 307.3 to 409.3 & -1.3 to 6.6 & \\
\hline \multicolumn{8}{|c|}{ \% Peak Power Level of MVIC (W) } \\
\hline 40 & $\begin{array}{c}266.2 \\
234.5 \text { to } 297.9\end{array}$ & $\begin{array}{c}317.5 \\
280.1 \text { to } 354.9^{*}\end{array}$ & $\begin{array}{c}21.8 \\
7.9 \text { to } 35.7^{\dagger}\end{array}$ & $\begin{array}{c}278.5 \\
248.6 \text { to } 308.4\end{array}$ & $\begin{array}{c}269.1 \\
228.2 \text { to } 310.0\end{array}$ & $\begin{array}{c}-4.7 \\
-12.6 \text { to } 3.2\end{array}$ & 1.127 \\
\hline 50 & $\begin{array}{c}288.0 \\
252.2 \text { to } 323.8\end{array}$ & $\begin{array}{c}324.8 \\
288.6 \text { to } 361.0^{*}\end{array}$ & $\begin{array}{c}14.5 \\
5.0 \text { to } 24.0^{\dagger}\end{array}$ & $\begin{array}{c}291.9 \\
257.0 \text { to } 326.7\end{array}$ & $\begin{array}{c}279.8 \\
236.8 \text { to } 322.8\end{array}$ & $\begin{array}{c}-4.7 \\
-1.6 \text { to } 2.2\end{array}$ & 1.109 \\
\hline 60 & $\begin{array}{c}276.3 \\
241.8 \text { to } 310.7\end{array}$ & $\begin{array}{c}321.8 \\
280.5 \text { to } 363.1^{*}\end{array}$ & $\begin{array}{c}17.3 \\
8.9 \text { to } 25.6^{\dagger}\end{array}$ & $\begin{array}{c}287.5 \\
246.8 \text { to } 328.1\end{array}$ & $\begin{array}{c}278.9 \\
227.4 \text { to } 330.4\end{array}$ & $\begin{array}{c}-3.4 \\
-12.2 \text { to } 5.4\end{array}$ & 1.160 \\
\hline 70 & $\begin{array}{c}237.1 \\
205.0 \text { to } 269.2\end{array}$ & $\begin{array}{l}274.3 \\
243.2 \text { to } 305.4^{*}\end{array}$ & $\begin{array}{c}19.4 \\
3.9 \text { to } 34.8^{\dagger}\end{array}$ & $\begin{array}{c}267.8 \\
227.5 \text { to } 308.1\end{array}$ & $\begin{array}{c}240.2 \\
191.0 \text { to } 289.3\end{array}$ & $\begin{array}{l}-10.9 \\
-20.8 \text { to }-1.0\end{array}$ & 1.228 \\
\hline 80 & $\begin{array}{c}211.5 \\
176.6 \text { to } 246.5\end{array}$ & $\begin{array}{c}242.0 \\
195.1 \text { to } 288.9^{*}\end{array}$ & $\begin{array}{c}22.3 \\
-2.9 \text { to } 47.5^{\dagger}\end{array}$ & $\begin{array}{c}223.8 \\
171.4 \text { to } 276.2\end{array}$ & $\begin{array}{c}189.2 \\
136 \text { to } 242.4\end{array}$ & $\begin{array}{c}-14.2 \\
-28.7 \text { to } 0.4\end{array}$ & 1.071 \\
\hline \multicolumn{8}{|c|}{$\begin{array}{l}\text { Note: ES was calculated for change baseline posttraining valu } \\
{ }^{*} \text { Difference to baseline within group. } \\
{ }^{\dagger} \text { Exercise group to control group difference. } \\
\text { ES = effect size, MVIC = maximal voluntary isometric contra }\end{array}$} \\
\hline
\end{tabular}

12 wk of muscle power training in patients with relapsing-remitting MS. Although increments in strength and muscle power after a resistance training program have already been shown in patients with MS [36-39], training adaptations to muscle power training in patients with MS had not yet been studied. In addition, this is the first study that provides muscle power values at five different rela- tive loads in patients with MS that had previously carried out a muscle power training program.

The increments reported in the current investigation in MVIC after the intervention, i.e., EG, support data from previous studies in elderly nondisabled subjects that showed relevant increases in knee extensors muscle strength following high-speed power training [27]. That
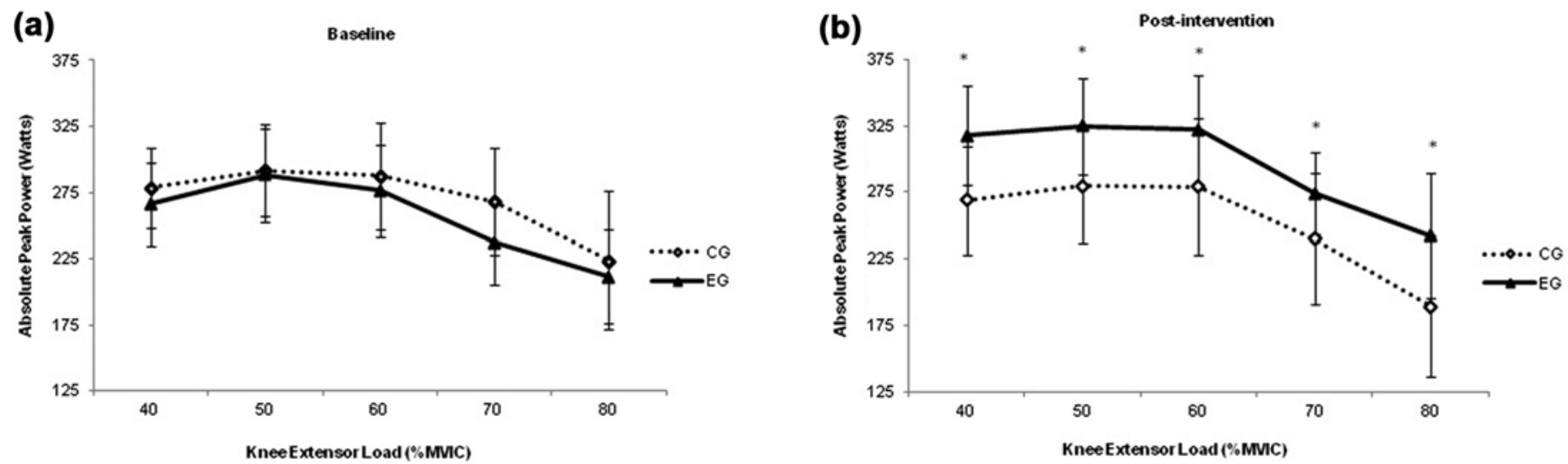

Figure 2.

Knee extension load power curves. Exercise group (EG) and control group (CG) peak power values at loads corresponding to 40\%$80 \%$ of maximum voluntary isometric knee extension contraction (a) before and (b) after 12 wk of muscle power training. Values are means \pm standard deviation expressed in watts. ${ }^{*}$ Change baseline to postintervention (\%) in EG vs CG difference. $p<0.05$. MVIC $=$ maximum voluntary isometric contraction. 
study reported greater increases in muscle power than those described in the current study (25\% vs $11 \%)$. Disparity between studies may be explained by characteristics of subjects since functional exercise capacity of patients with MS is reduced compared with nondisabled controls [40]. In addition, the training protocol employed by Henwood et al. [27] was longer than the one used in this investigation (16 wk vs $12 \mathrm{wk}$ ). Notwithstanding, our data support previous studies that reported significant increases in isometric muscle strength after progressive resistance training in patients with MS [22-23,3637,39,41]. Hence, both training protocols (high-speed power training and progressive resistance training) seem to induce similar isometric strength adaptations in patients with MS (from $11 \%$ to $17 \%$ ). It is generally believed that MVIC increases after resistance exercise training in patients with MS are caused by neural adaptations rather than by increased muscle mass [22,34,36,42]. This notion seems to explain isometric force gains in other populations as well, such as in adult nondisabled subjects [43-45].

The EG improved peak muscle power after the training protocol in the five submaximal loads analyzed. These adaptations resemble those reported by others in a nondisabled population [26-27,46-47]. However, power increments in the nondisabled population are usually greater than the changes reported here. Several factors, including neural and muscular impairments such as important strength deficits during dynamic muscle action [5] caused by the MS disease [48], may account for these differences. In addition, potential methodological differences during testing protocols should also be considered. Given that this is the first study analyzing power adaptations at different loads in patients with MS, it is difficult to elucidate the mechanisms behind such adaptations. Studies assessing nondisabled populations suggest that early rises in muscle power are primarily independent of muscle mass $[34,49]$. If this holds true for patients with MS, the mechanisms behind the muscle power adaptations described in the current investigation would have a neuromuscular origin [47]. Indeed, and although studies regarding neuromuscular adaptations in patients with MS are scarce [31], it has been suggested that resistance training increases the maximal neural drive in lower-limb muscles of patients with MS [34,50]. Moreover, some studies have failed to show a clear relationship between the increments in muscle cross-sectional area and muscle strength gains in patients with MS after progressive resis- tance training $[22,41]$. Hence, muscle strength adaptations after progressive resistance training in patients with MS are often associated with neural mechanisms [22].

Despite the mechanisms controlling the adaptations, the enhancement of muscle power after training may contribute to maintaining or improving function during everyday tasks in patients with MS, as it has been described in elderly, nondisabled subjects [22,26,51]. Indeed, muscle power, or the maximum capacity to perform work per unit of time in muscles of the lower limbs, has been defined as an adequate predictor of functional independence in frail elderly people [51]. Therefore, the power training paradigm used in the present investigation supports the efficacy and safety of muscle power training programs as a therapeutic tool for patients with relapsingremitting MS.

There are some aspects that may limit the findings reported in this investigation. First, all participants were recruited among MS rehabilitation centers and may not represent all patients with MS, in particular those who are physically independent or who are severely impaired. Second, the participants were not blinded to the intervention. Third, functional tasks were not assessed. Thus, future studies should address the physiological and neurological mechanisms responsible for adaptations induced by muscular power training programs and discuss such effects based on duration of training (short-term and longterm), age, sex, or training status in patients with MS. In addition, there is a need to compare different resistance training programs to evaluate the specificity of each type of training. Finally, the potential relationship between peak muscle power increments and functional capacity needs to be addressed.

\section{CONCLUSIONS}

This study showed for the first time that a muscle power training protocol of $12 \mathrm{wk}$ increased maximal strength and muscle power in patients with relapsingremitting MS. Despite some limitations, this novel investigation describes the training responses of patients with relapsing-remitting MS after a muscle power training program, with results supporting the use of muscle power training protocols in these patients to increase muscle force and power. 


\section{ACKNOWLEDGMENTS}

\section{Author Contributions:}

Study concept and design: C. Medina-Perez, J. A. de Paz-Fernandez. Acquisition of data: C. Medina-Perez, F. de Souza-Teixeira,

J. A. Hernandez-Murua.

Analysis and interpretation of data: C. Medina-Perez,

J. A. Hernandez-Murua.

Drafting of manuscript: C. Medina Perez, R. Fernandez-Gonzalo. Critical revision of manuscript for important intellectual content: C. Medina-Perez, F. de Souza-Teixeira, R. Fernandez-Gonzalo, J. A. Hernandez-Murua, J. A. de Paz-Fernandez.

Statistical analysis: R. Fernandez-Gonzalo.

Obtained funding: F. de Souza-Teixeira, J. A. de Paz-Fernandez.

Study supervision: F. de Souza-Teixeira, J. A. de Paz-Fernandez.

Financial Disclosures: The authors have declared that no competing interests exist.

Funding/Support: This material was based on work supported by the Consejería de Sanidad y Consumo, Government of Castilla y León, Spain.

Additional Contributions: The authors are grateful to Consejería de Sanidad y Consumo. Government of Castilla y León (Spain) and to all patients enrolled in the study.

Institutional Review: The study was approved by the Research Ethics Committee at the University of León. Participants signed written informed consent.

Participant Follow-Up: The authors do not plan to inform participants of the publication of this study. However, participants have been encouraged to check the study Web site for updated publications.

\section{REFERENCES}

1. Heesen C, Böhm J, Reich C, Kasper J, Goebel M, Gold SM. Patient perception of bodily functions in multiple sclerosis: Gait and visual function are the most valuable. Mult Scler. 2008;14(7):988-91. [PMID:18505775] http://dx.doi.org/10.1177/1352458508088916

2. Gunn H, Creanor S, Haas B, Marsden J, Freeman J. Frequency, characteristics, and consequences of falls in multiple sclerosis: Findings from a cohort study. Arch Phys Med Rehabil. 2014;95(3):538-45. [PMID:24055784] http://dx.doi.org/10.1016/j.apmr.2013.08.244

3. Cavanaugh JT, Gappmaier VO, Dibble LE, Gappmaier E. Ambulatory activity in individuals with multiple sclerosis. J Neurol Phys Ther. 2011;35(1):26-33. [PMID:21475081] http://dx.doi.org/10.1097/NPT.0b013e3182097190

4. Göksel Karatepe A, Kaya T, Günaydn R, Demirhan A, Ce P, Gedizlioğlu M. Quality of life in patients with multiple sclerosis: The impact of depression, fatigue, and disability. Int J Rehabil Res. 2011;34(4):290-98. [PMID:21946317] http://dx.doi.org/10.1097/MRR.0b013e32834ad479

5. Chung LH, Remelius JG, Van Emmerik RE, Kent-Braun JA. Leg power asymmetry and postural control in women with multiple sclerosis. Med Sci Sports Exerc. 2008; 40(10):1717-24. [PMID:18799980]

http://dx.doi.org/10.1249/MSS.0b013e31817e32a3

6. Ng AV, Miller RG, Gelinas D, Kent-Braun JA. Functional relationships of central and peripheral muscle alterations in multiple sclerosis. Muscle Nerve. 2004;29(6):843-52.

[PMID:15170617]

http://dx.doi.org/10.1002/mus.20038

7. Lambert CP, Archer RL, Evans WJ. Muscle strength and fatigue during isokinetic exercise in individuals with multiple sclerosis. Med Sci Sports Exerc. 2001;33(10):1613-19. [PMID:11581542] http://dx.doi.org/10.1097/00005768-200110000-00001

8. Armstrong LE, Winant DM, Swasey PR, Seidle ME, Carter AL, Gehlsen G. Using isokinetic dynamometry to test ambulatory patients with multiple sclerosis. Phys Ther. 1983;63(8):1274-79. [PMID:6878438]

9. Ponichtera JA, Rodgers MM, Glaser RM, Mathews TA, Camaione DN. Concentric and eccentric isokinetic lower extremity strength in persons with multiple sclerosis. J Orthop Sports Phys Ther. 1992;16(3):114-22.

[PMID:18796767]

http://dx.doi.org/10.2519/jospt.1992.16.3.114

10. Bean JF, Kiely DK, Herman S, Leveille SG, Mizer K, Frontera WR, Fielding RA. The relationship between leg power and physical performance in mobility-limited older people. J Am Geriatr Soc. 2002;50(3):461-67. [PMID:11943041] http://dx.doi.org/10.1046/j.1532-5415.2002.50111.x

11. Scott SM, Hughes AR, Galloway SD, Hunter AM. Surface EMG characteristics of people with multiple sclerosis during static contractions of the knee extensors. Clin Physiol Funct Imaging. 2011;31(1):11-17. [PMID:20807227] http://dx.doi.org/10.1111/j.1475-097X.2010.00972.x

12. Garner DJ, Widrick JJ. Cross-bridge mechanisms of muscle weakness in multiple sclerosis. Muscle Nerve. 2003; 27(4):456-64. [PMID:12661047] http://dx.doi.org/10.1002/mus.10346

13. Kjølhede T, Vissing K, de Place L, Pedersen BG, Ringgaard S, Stenager E, Petersen T, Dalgas U. Neuromuscular adaptations to long-term progressive resistance training translates to improved functional capacity for people with multiple sclerosis and is maintained at follow-up. Mult Scler. 2015;21(5):599-611. [PMID:25257612] http://dx.doi.org/10.1177/1352458514549402

14. Foldvari M, Clark M, Laviolette LC, Bernstein MA, Kaliton D, Castaneda C, Pu CT, Hausdorff JM, Fielding RA, Singh MA. Association of muscle power with functional status in community-dwelling elderly women. J Gerontol A Biol Sci Med Sci. 2000;55(4):M192-99.

[PMID:10811148] http://dx.doi.org/10.1093/gerona/55.4.M192 
15. Suzuki T, Bean JF, Fielding RA. Muscle power of the ankle flexors predicts functional performance in communitydwelling older women. J Am Geriatr Soc. 2001;49(9): 1161-67. [PMID:11559374] http://dx.doi.org/10.1046/j.1532-5415.2001.49232.x

16. Van Roie E, Verschueren SM, Boonen S, Bogaerts A, Kennis E, Coudyzer W, Delecluse C. Force-velocity characteristics of the knee extensors: An indication of the risk for physical frailty in elderly women. Arch Phys Med Rehabil. 2011;92(11):1827-32. [PMID:22032216] http://dx.doi.org/10.1016/j.apmr.2011.05.022

17. Caserotti P, Aagaard P, Larsen JB, Puggaard L. Explosive heavy-resistance training in old and very old adults: Changes in rapid muscle force, strength and power. Scand J Med Sci Sports. 2008;18(6):773-82. [PMID:18248533] http://dx.doi.org/10.1111/j.1600-0838.2007.00732.x

18. Warburton DE, Gledhill N, Quinney A. Musculoskeletal fitness and health. Can J Appl Physiol. 2001;26(2):217-37. [PMID:11312417] http://dx.doi.org/10.1139/h01-013

19. Izquierdo M, Häkkinen K, Ibañez J, Garrues M, Antón A, Zúñiga A, Larrión JL, Gorostiaga EM. Effects of strength training on muscle power and serum hormones in middleaged and older men. J Appl Physiol (1985). 2001;90(4): 1497-1507. [PMID:11247952]

20. Sayers SP, Gibson K. High-speed power training in older adults: A shift of the external resistance at which peak power is produced. J Strength Cond Res. 2014;28(3):616-21. [PMID:23897022] http://dx.doi.org/10.1519/JSC.0b013e3182a361b8

21. Cadore EL, Casas-Herrero A, Zambom-Ferraresi F, Idoate F, Millor N, Gómez M, Rodriguez-Mañas L, Izquierdo M. Multicomponent exercises including muscle power training enhance muscle mass, power output, and functional outcomes in institutionalized frail nonagenarians. Age (Dordr). 2014;36(2):773-85. [PMID:24030238] http://dx.doi.org/10.1007/s11357-013-9586-z

22. de Souza-Teixeira F, Costilla S, Ayán C, García-López D, González-Gallego J, de Paz JA. Effects of resistance training in multiple sclerosis. Int J Sports Med. 2009; 30(4): 245-50. [PMID:19199197] http://dx.doi.org/10.1055/s-0028-1105944

23. Medina-Perez C, de Souza-Teixeira F, Fernandez-Gonzalo $\mathrm{R}$, de Paz-Fernandez JA. Effects of a resistance training program and subsequent detraining on muscle strength and muscle power in multiple sclerosis patients. NeuroRehabilitation. 2014;34(3):523-30. [PMID:24463236]

24. Porter MM. Power training for older adults. Appl Physiol Nutr Metab. 2006;31(2):87-94. [PMID:16604125] http://dx.doi.org/10.1139/h05-034

25. American College of Sports Medicine. American College of Sports Medicine position stand. Progression models in resistance training for healthy adults. Med Sci Sports
Exerc. 2009;41(3):687-708. [PMID:19204579]

http://dx.doi.org/10.1249/MSS.0b013e3181915670

26. Pereira A, Izquierdo M, Silva AJ, Costa AM, Bastos E, González-Badillo JJ, Marques MC. Effects of high-speed power training on functional capacity and muscle performance in older women. Exp Gerontol. 2012;47(3):250-55. [PMID:22234287]

http://dx.doi.org/10.1016/j.exger.2011.12.010

27. Henwood TR, Riek S, Taaffe DR. Strength versus muscle power-specific resistance training in community-dwelling older adults. J Gerontol A Biol Sci Med Sci. 2008;63(1): 83-91. [PMID:18245765]

http://dx.doi.org/10.1093/gerona/63.1.83

28. Ramírez-Campillo R, Castillo A, de la Fuente CI, CamposJara C, Andrade DC, Álvarez C, Martínez C, CastroSepúlveda M, Pereira A, Marques MC, Izquierdo M. Highspeed resistance training is more effective than low-speed resistance training to increase functional capacity and muscle performance in older women. Exp Gerontol. 2014; 58:51-57. [PMID:25014621]

http://dx.doi.org/10.1016/j.exger.2014.07.001

29. Wallerstein LF, Tricoli V, Barroso R, Rodacki A LF, Russo L, Aihara AY, da Rocha Correa Fernandes A, de Mello MT, Ugrinowitsch C. Effects of strength and power training on neuromuscular variables in older adults. J Aging Phys Act. 2012;20(2):171-85. [PMID:22472578]

30. Sayers SP, Gibson K. A comparison of high-speed power training and traditional slow-speed resistance training in older men and women. J Strength Cond Res. 2010;24(12): 3369-80. [PMID:21068681] http://dx.doi.org/10.1519/JSC.0b013e3181f00c7c

31. Kjølhede T, Vissing K, Dalgas U. Multiple sclerosis and progressive resistance training: A systematic review. Mult Scler. 2012;18(9):1215-28. [PMID:22760230] http://dx.doi.org/10.1177/1352458512437418

32. McDonald WI, Compston A, Edan G, Goodkin D, Hartung HP, Lublin FD, McFarland HF, Paty DW, Polman $\mathrm{CH}$, Reingold SC, Sandberg-Wollheim M, Sibley W, Thompson A, van den Noort S, Weinshenker BY, Wolinsky JS. Recommended diagnostic criteria for multiple sclerosis: Guidelines from the International Panel on the diagnosis of multiple sclerosis. Ann Neurol. 2001;50(1):121-27. [PMID: 11456302] http://dx.doi.org/10.1002/ana.1032

33. Fernandez-Gonzalo R, Bresciani G, de Souza-Teixeira F, Hernandez-Murua JA, Jimenez-Jimenez R, Gonzalez-Gallego J, de Paz JA. Effects of a 4-week eccentric training program on the repeated bout effect in young active women. J Sports Sci Med. 2011;10(4):692-99. [PMID:24149560]

34. Petrella JK, Kim JS, Tuggle SC, Bamman MM. Contributions of force and velocity to improved power with progressive resistance training in young and older adults. Eur J 
Appl Physiol. 2007;99(4):343-51. [PMID:17165058]

http://dx.doi.org/10.1007/s00421-006-0353-z

35. Cohen J. Statistical power analysis for the behavioral sciences. Revised ed. London (UK): Academic Press; 1977.

36. Broekmans T, Roelants M, Feys P, Alders G, Gijbels D, Hanssen I, Stinissen P, Eijnde BO. Effects of long-term resistance training and simultaneous electro-stimulation on muscle strength and functional mobility in multiple sclerosis. Mult Scler. 2011;17(4):468-77. [PMID:21148266] http://dx.doi.org/10.1177/1352458510391339

37. Dalgas U, Stenager E, Jakobsen J, Petersen T, Hansen HJ, Knudsen C, Overgaard K, Ingemann-Hansen T. Resistance training improves muscle strength and functional capacity in multiple sclerosis. Neurology. 2009;73(18):1478-84. [PMID:19884575] http://dx.doi.org/10.1212/WNL.0b013e3181bf98b4

38. DeBolt LS, McCubbin JA. The effects of home-based resistance exercise on balance, power, and mobility in adults with multiple sclerosis. Arch Phys Med Rehabil. 2004;85(2):290-97. [PMID:14966716] http://dx.doi.org/10.1016/j.apmr.2003.06.003

39. Filipi ML, Kucera DL, Filipi EO, Ridpath AC, Leuschen MP. Improvement in strength following resistance training in MS patients despite varied disability levels. NeuroRehabilitation. 2011;28(4):373-82. [PMID:21725171]

40. Bosnak-Guclu M, Gunduz AG, Nazliel B, Irkec C. Comparison of functional exercise capacity, pulmonary function and respiratory muscle strength in patients with multiple sclerosis with different disability levels and healthy controls. J Rehabil Med. 2012;44(1):80-86. [PMID:22234321] http://dx.doi.org/10.2340/16501977-0900

41. Dalgas U, Stenager E, Lund C, Rasmussen C, Petersen T, Sørensen H, Ingemann-Hansen T, Overgaard K. Neural drive increases following resistance training in patients with multiple sclerosis. J Neurol. 2013;260(7):1822-32. [PMID:23483214] http://dx.doi.org/10.1007/s00415-013-6884-4

42. Dalgas U, Stenager E, Jakobsen J, Petersen T, Overgaard $\mathrm{K}$, Ingemann-Hansen T. Muscle fiber size increases following resistance training in multiple sclerosis. Mult Scler. 2010;16(11):1367-76. [PMID:20685760] http://dx.doi.org/10.1177/1352458510377222

43. Marsh AP, Miller ME, Rejeski WJ, Hutton SL, Kritchevsky SB. Lower extremity muscle function after strength or power training in older adults. J Aging Phys Act. 2009; 17(4):416-43. [PMID:19940322]

44. Phillips SM. Short-term training: When do repeated bouts of resistance exercise become training? Can J Appl Physiol. 2000;25(3):185-93. [PMID:10932036] http://dx.doi.org/10.1139/h00-014

45. Moritani T, deVries HA. Potential for gross muscle hypertrophy in older men. J Gerontol. 1980;35(5):672-82.

\section{[PMID:7430562]}

http://dx.doi.org/10.1093/geronj/35.5.672

46. Earles DR, Judge JO, Gunnarsson OT. Velocity training induces power-specific adaptations in highly functioning older adults. Arch Phys Med Rehabil. 2001;82(7):872-78. [PMID:11441371] http://dx.doi.org/10.1053/apmr.2001.23838

47. Fielding RA, LeBrasseur NK, Cuoco A, Bean J, Mizer K, Fiatarone Singh MA. High-velocity resistance training increases skeletal muscle peak power in older women. J Am Geriatr Soc. 2002;50(4):655-62. [PMID:11982665] http://dx.doi.org/10.1046/j.1532-5415.2002.50159.x

48. Kent-Braun JA, Ng AV, Castro M, Weiner MW, Gelinas D, Dudley GA, Miller RG. Strength, skeletal muscle composition, and enzyme activity in multiple sclerosis. J Appl Physiol (1985). 1997;83(6):1998-2004. [PMID:9390973]

49. De Vito G, Bernardi M, Forte R, Pulejo C, Figura F. Effects of a low-intensity conditioning programme on $\mathrm{VO} 2 \mathrm{max}$ and maximal instantaneous peak power in elderly women. Eur J Appl Physiol Occup Physiol. 1999;80(3):227-32. [PMID:10453925] http://dx.doi.org/10.1007/s004210050586

50. Fimland MS, Helgerud J, Gruber M, Leivseth G, Hoff J. Enhanced neural drive after maximal strength training in multiple sclerosis patients. Eur J Appl Physiol. 2010; 110(2):435-43. [PMID:20512584] http://dx.doi.org/10.1007/s00421-010-1519-2

51. Reid KF, Callahan DM, Carabello RJ, Phillips EM, Frontera WR, Fielding RA. Lower extremity power training in elderly subjects with mobility limitations: A randomized controlled trial. Aging Clin Exp Res. 2008;20(4):337-43. [PMID:18852547] http://dx.doi.org/10.1007/BF03324865

Submitted for publication August 14, 2014. Accepted in revised form July 16, 2015.

This article and any supplementary material should be cited as follows:

Medina-Perez C, de Souza-Teixeira F, Fernandez-Gonzalo R, Hernandez-Murua J, de Paz-Fernandez JA. Effects of high-speed power training on muscle strength and power in patients with multiple sclerosis. J Rehabil Res Dev. 2016;53(3):359-68.

http://dx.doi.org/10.1682/JRRD.2014.08.0186

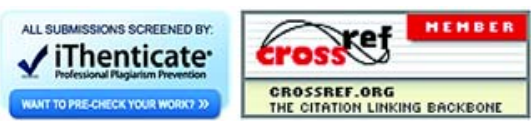

